\title{
Monolitik CAD/CAM Bloklara Uygulanan Farklı Yüzey Uygulamaları ve Simanlarla Bağlantı Kuvvetine Güncel Bakış
}

\section{Current Insight into Different Surface Treatments of Monolithic CAD/CAM Blocks and Bond Strength with Cements}

\author{
Şehrize Dilara UĞUZ, Volkan TURP
}

İstanbul Üniversitesi, Diş Hekimliği Fakültesi Protetik Diş Tedavisi Anabilim Dalı, İstanbul, Türkiye

Yazıșma Adresi

Correspondence Address

\section{Şehrize Dilara UĞUZ}

İstanbul Üniversitesi, Diş Hekimliği

Fakültesi, Protetik Diş Tedavisi

Anabilim Dalı, İstanbul, Türkiye

d_uguz@hotmail.com

Geliş tarihi / Received : Mart 01, 2021 Kabul tarihi / Accepted : Mart 30, 2021 Elektronik yayın tarihi : Ocak 01, 2022 Online published

Bu makalede yapılacak atıf:

Cite this article as:

Uğuz Ș, D, Turp V.

Monolitik CAD/CAM Bloklara

Uygulanan Farklı Yüzey

Uygulamaları ve Simanlarla

Bağlantı Kuvvetine Güncel Bakıș.

Akd Tip D 2022; 8(1):91-100.

Sehrize Dilara Uğuz

ORCID 0000-0001-5598-3516

Volkan Turp

ORCID 0000-0001-5636-010X

\section{Öz}

\section{Giriş/Amaç:}

Doğal dişi her yönüyle taklit eden materyal arayışları günümüzde monolitik olarak kullanılabilen farklı üreticilere ait cam, reçine infiltre, zirkonya seramikler ile zirkonyayla güçlendirilmiş lityum disilikat seramiklerin ortaya çıkışına yol açmıştır. Bu materyaller kullanılarak yapılan restorasyonların başarısı ise, en başta uygulanan restorasyonun yerinde kalması, diğer bir deyişle bağlantı dayanımı, tarafından belirlenmektedir. Tümü güncel olan ve rutin klinik kullanıma sahip bu materyallerin bağlantı dayanımını artırmak için pek çok yöntem denenmeye devam etmektedir. Bağlantı dayanımını artıran yöntemler arasında mekanik işlemler olarak; kumlama, döner alet ile pürüzlendirme ve lazer uygulama, kimyasal işlemler olarak; hidroflorik asit (HF) ile pürüzlendirme, tribokimyasal silika ile kaplama ve silan bağlayıcı ajan kullanımı üzerinde araştırmalar mevcuttur. Çalışmalara göre mekanik ve kimyasal işlemler sonucunda elde edilen yüzey özelliklerine göre başarıyı etkileyen bağlantı dayanımı da önemli derecede değişmektedir. Bu derlemede farklı yüzey işlemleri sonrası CAD/CAM monolitik seramiklerin reçine siman ile bağlantı dayanımı ve çalışma yöntemleri üzerinde daha önce yapılmış çalışmalar ışığında güncel bir bilgi sunulması amaçlanmıştır.

Anahtar Sözcülkler: Monolitik restorasyon, Bağlantı dayanımı, Termal döngü

\begin{abstract}
Researches to develop the materials mimicking all the features of natural tooth structure have resulted in the evolution of monolithic glass, resin infiltrated, zirconia and zirconia reinforced lithium disilicate ceramics. The success of the restorations made of these materials greatly depends on the restorations to be held in position, in other words the bond strength. There are many studies to improve the bond strength of these recent and routine clinical materials in the dental literature. According to the studies one of the factor determining the success of restoration, bond strength, is affected from the surfaces created by chemical and mechanical treatments. The surface treatment studies using the mechanical processes such as sandblasting, grinding and laser application and chemical processes such as hydrofluoric acid (HF) application, tribochemical silica coating and the use of silane coupling agent were performed in the past. The aim of the present review was giving a current knowledge to the authors about the bond strength and research methods of resin and CAD/CAM monolithic ceramics in the lights of the previous studies.
\end{abstract}

Key Words: Monolithic restoration, Bond strenght, Termocycling 


\section{GIRIŞ}

Günümüzde CAD/CAM (bilgisayar destekli tasarım/bilgisayar destekli üretim) teknolojisinde görülen gelişmeler ve yeni seramik esaslı materyallerin kullanıma sunulmasıyla birlikte üst yapı seramiği ile tabakalama gereksinimi olmayan ve tek seansta üretilip simante edilebilen monolitik restorasyonlar önem kazanmıştır. Monolitik restorasyonların kullanımıyla birlikte, üst yapı seramiğinde görülen kırılmaların ortadan kalkacağı ve karşıt çenede var olan dişlerde görülebilen aşınmaların en aza indirgenebileceği düşünülmüştür (1-5). Monolitik ve tabakalanmış restorasyonlar kullanılacakları bölgeye, çeneler arası mesafenin durumuna ve hastaların alışkanlıklarına göre tercih edilebilmektedir. Bu derlemenin amac1, seramik esaslı monolitik CAD/CAM bloklara uygulanan yüzey uygulamalarının ve simanlarla bağlantı kuvvetinin güncel literatür desteği ile değerlendirilmesidir.

Ön bölge restorasyonlarda estetik beklenti yüksektir. Doğal diş dokularının tüm özellikleri taklit edilmeye çalış1ır. Tabakalanmış restorasyonlarda doğala daha yakın sonuçlar elde etmek mümkün olduğu için ön bölgede sıklıkla tercih edilirler. Çeneler arası mesafelerin kısıtlandığı durumlarda, üst yapı seramiği için yeterli mesafe yok ise monolitik restorasyonlar tercih edilebilmektedir. Parafonksiyonel alışkanlıklara sahip hastalarda üst yap1 seramiğinde kirılmalar sıklıkla görülebilmektedir. Monolitik restorasyonlar, bu durumun önüne geçilmesini sağlar. Üst yap1 porseleni makaslama kuvvetleri altında 90 ile $140 \mathrm{MPa}$ arasında dayanım gösterir. Monolitik restorasyonların dayanımı 380 ile $1000 \mathrm{MPa}$ arasında değişmektedir. Bu sebeple de arka bölge restorasyonlarda tercih edilebilmektedirler $(2,5,6)$.

Monolitik olarak sabit protetik tedavide kullanılabilen seramik esaslı materyaller (7) (Tablo I).

Tablo I: CAD/CAM destekli monolitik olarak kullanılabilen seramik esaslı materyaller.

\begin{tabular}{|c|c|c|c|c|}
\hline \multirow[t]{4}{*}{ MATERYALLER } & Cam seramikler & $\begin{array}{c}\text { Zirkonya ile } \\
\text { güçlendirilmiş } \\
\text { lityum disilikat }\end{array}$ & $\begin{array}{c}\text { Reçine infiltre } \\
\text { seramikler }\end{array}$ & Zirkonya \\
\hline & $\begin{array}{l}\text { Feldspatik } \\
\text { TriLuxe forte- Real } \\
\text { Life, VITA } \\
\text { Zahnfabrik } \\
\text { Cerec PC, Dentsply } \\
\text { Sirona }\end{array}$ & $\begin{array}{l}\text { Suprinity,VITA } \\
\text { Celtra Duo, } \\
\text { Dentsply }\end{array}$ & $\begin{array}{l}\text { Reçine nano } \\
\text { seramik } \\
\text { Lava Ultimate } \\
\text { 3M, ESPE } \\
\text { Cerasmart, GC }\end{array}$ & $\begin{array}{l}\text { Katana } \\
\text { Zirconia } \\
\text { ML, } \\
\text { Noritake } \\
\\
\text { Cercon ht, } \\
\text { Dentsply }\end{array}$ \\
\hline & $\begin{array}{l}\text { Lösit } \\
\text { IPS Empress CAD, } \\
\text { Ivoclar Vivadent }\end{array}$ & & $\begin{array}{l}\text { Hibrit seramik } \\
\text { Enamic, VITA } \\
\text { Zahnfabrik }\end{array}$ & $\begin{array}{l}\text { Prettau } \\
\text { Zirconia, } \\
\text { Zirkonzahn }\end{array}$ \\
\hline & $\begin{array}{l}\text { Lityum disilikat } \\
\text { IPS e.max CAD, } \\
\text { Ivoclar Vivadent } \\
\text { 3G HS, Pentron } \\
\text { Ceramics }\end{array}$ & & 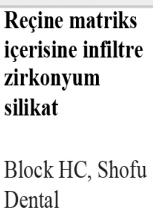 & $\begin{array}{l}\text { IPS e.max } \\
\text { ZirCAD, } \\
\text { Ivoclar } \\
\text { Vivadent }\end{array}$ \\
\hline
\end{tabular}

1.Cam seramikler

a. Feldspatik seramik

b. Lösit ile güçlendirilmiş cam seramik

c. Lityum disilikat ile güçlendirilmiş cam seramik

2. Zirkonya ile güçlendirilmiş lityum disilikat

3. Reçine infiltre seramikler

a. Reçine nano seramik

b. Reçine matriks içerisine infilttre edilmiş cam seramik; hibrit seramik

c. Reçine matriks içerisine infiltre edilmiş zirkonyum silikat 4. Zirkonya

Tam seramik sistemlerin simantasyonunda; optik özelliklerinin yüksek olması, geleneksel simanlara göre daha az mikro sızıntı göstermeleri ve kırılma dayanımlarının daha yüksek oluşu sebebiyle reçine siman ile adeziv simantasyon protokolü önerilmektedir. Adeziv simantasyon öncesi restorasyon iç yüzeyine belirli uygulamalar yapılması gerekmektedir $(8,9)$.

\section{Restorasyon İç Yüzüne Uygulanan}

Yüzey İşlemleri

Sabit protetik restorasyonların iç yüzeyine uygulanan işlemler, simanlar ile mekanik ve kimyasal bağlantı oluşumuna katkıda bulunmalarına göre iki şekilde gruplandırılabilir (10) (Tablo II).

Tablo II: Restorasyon iç yüzeyinde kimyasal ve mekanik bağlantı oluşturan yüzey işlemleri.

\begin{tabular}{|l|l|l|}
\hline YÜZEY IŞSLMLERI & Mekanik bağlantı oluşturan & Kimyasal bağlantı oluşturan \\
\cline { 2 - 3 } & $\begin{array}{l}\text { Al203 partikülleriyle } \\
\text { pürüzlendirme(kumlama) }\end{array}$ & HF asit ile pürüzlendirme \\
\hline & $\begin{array}{l}\text { Döner aletler ile pürüzlendirme } \\
\text { Lazer ile pürüzlendirme }\end{array}$ & Tribokimyasal silika ile kaplama \\
\hline & Silan bağlayıcı ajanlar \\
\hline
\end{tabular}

1. Mekanik bağlantı oluşturan işlemler

a. Alüminyum oksit (AL2O3) partikülleriyle

b. Döner alet ile pürüzlendirme

c. Lazer ile pürüzlendirmedir.

2. Kimyasal bağlantı oluşturan işlemler:

a. Hidroflorik asit (HF) ile pürüzlendirme

b. Tribokimyasal silika ile kaplama

c. Silan bağlayıcı ajanların kullanılmasıdır.

1. Mekanik bağlantı oluşturan yüzey işlemleri a. Alüminyum oksit partikülleriyle pürüzlendirme

Restorasyon iç yüzünün alüminyum oksit partikülleriyle kumlanması, bir ön yüzey işlemidir. Pürüzlendirme sonucu yüzey alanı artar, mikro mekanik bağlantı sağlanır ve kontaminasyon tabakası da ortadan kalkmış olur (11).

Kumlama işleminde 30 ila $110 \mu \mathrm{m}$ arasında değişen tanecik büyüklüğüne sahip alüminyum oksit partiküllerinin, 0.28 MPa basınçla ortalama $15 \mathrm{~mm}$ mesafeden 10 saniye boyunca yüzeye püskürtülmesi önerilmektedir (12). 


\section{b. Döner alet ile pürüzlendirme}

Döner aletler yardımıyla yüzey pürüzlendirme işlemi; zımpara, disk ve elmas frez yardımıyla yapılabilmektedir. Klinik ortamda uygulanabilmesi bu yöntemin avantajıdır. Kumlama ve döner aletlerle pürüzlendirme sonucunda seramik yüzeyinde çatlaklar oluşabilmekte ve restorasyonun kırılma dayanımı azalabilmektedir $(8,10)$.

\section{c. Lazer ile pürüzlendirme}

Lazer ile pürüzlendirme işlemi; yüzey alanının arttırılıp, mikro mekanik retansiyonun sağlanması amacıyla yapılmaktadır. Yüzey pürüzlendirmede kullanılan yüksek güçte lazer tipleri; CO2, Nd:YAG, Er,Cr:YSGG veya Er:YAG lazerlerdir (13). Pek çok çalışmada lazer uygulanmasının, tam seramik materyallerin adeziv bağlanmasını olumlu anlamda etkilediği gösterilmiştir (16,17). Fakat artan yüzey pürüzlülüğüne bağlı olarak mekanik özelliklerin olumsuz etkilendiği, yüzey erimesi ve korozyon oluşabildiği de gözlenmiştir $(14,18)$.

\section{Kimyasal bağlantı oluşturan yüzey işlemleri a. Hidroflorik asit ile pürüzlendirme}

Cam seramiklerin hidroflorik asit ile pürüzlendirilmesi sonucu; yüzey pürüzlülüğü artar ve mikro mekanik bağlantı sağlanmış olur. Zirkonya gibi oksitli seramik gruplarının yüzeyinin asitlenmesi, yapıda camsı faz bulunmadığg için pürüzlülük yaratmaz. Hidroflorik asitler \%4-10 arasında değişen farklı konsantrasyonlarda bulunabilmektedirler. Seramiklerin asitlenme süreleri yapıdaki camsı fazın oranı ile doğru orantılı olarak artmaktadır. Ortalama 20 ile 60 saniye arasında değişen sürelerle seramiklerin asitlenmesi önerilmektedir (19). Cam seramiklere farklı konsantrasyon (\%4.9'dan \%16.8'e kadar değişen) ve sürelerde (5 saniye ile 2 dakika aras1) uygulanan HF asidin uygulanmasını değerlendiren bir çok çalışma yapılmıştır (20-23). Ancak \%4 ve \%10'luk HF asit konsantrasyonunda 1 veya 2 dakika boyunca asitleme yapılmasının en fazla bağlantı dayanımını sağladığı gösterilmiştir.

\section{b. Tribokimyasal silika ile kaplama}

Silika ile modifiye edilmiş alüminyum oksit partiküllerinin, seramik yüzeyine yüksek basınç ile püskürtülerek kumlanması işlemine tribokimyasal silika ile kaplama denir. Yüksek basınçta püskürtülen taneciklerin sahip olduğu kinetik enerji, yüzeye çarptıkları zaman 1sı enerjisine dönüşür ve tanecikler kısmen eriyerek yüzeye yapışırlar. Silika ile modifiye edilmiş alüminyum oksit tozları seramik yüzeyine gömülür ve silika ile kaplanmış bir yüzey elde edilir aynı zamanda mikro mekanik retansiyon alanı sağlanmış olunur (19). Silika ile kaplama CoJet ve Rocatec (3M-ESPE, Seefeld, Germany) sistemler sayesinde hem hasta başında hem de laboratuvarda uygulanabilmektedir. Hasta başında ortalama $30 \mu \mathrm{m}$ tanecik büyüklüğüne sahip CoJet kumunun 10-15 saniye boyunca restorasyona püskürtülmesi önerilmektedir (24). Rocatec sisteminde ise $110 \mu \mathrm{m}$ tanecik büyüklüğüne sahip kumla, 5 saniye süreyle iki aşamalı olarak yapılmaktadır. Önce Rocatec-Pre adı verilen alüminyum oksit tozları, sonra Rocatec-Plus adı verilen silisyum oksit kumları seramik iç yüzeyine püskürtülür (25).

\section{c. Silan bağlayıcı ajanlar}

Reçine siman ile cam seramikler arasında kimyasal bağlantı, silan bağlayıcı ajanlar sayesinde oluşturulur. Silanlar organik ve inorganik gruplar içeren bifonksiyonel ajanlardır. Seramik yüzeyine kondansasyon reaksiyonu ile silisyum hidroksil bazlı inorganik grup, reçine simana ise metakrilat içerikli organik gruplar bağlanır (19). Silanlar aynı zamanda yüzey enerjisini düşürerek yüzeyin ıslanabilirliğini arttırırlar. Bu durum da reçine simanın mikro mekanik retansiyonuna katk1da bulunur (10). Geleneksel silanlar, silika içerikli seramiklere göre daha kararlı yapıdadırlar ve kolaylıkla hidrolize olmazlar. Fakat zirkonyanin adeziv simantasyonunda etkili değildirler. Fosfat monomeri içeren (MDP içerikli) silan ve reçine simanların geleneksel olanlara göre daha kararlı yapıda olmaları, özellikle zirkonyanın adeziv simantasyonunda tercih edilme sebebidir. Fosfat monomeri içeren silan ve reçine siman kullanımının bağlantı dayanımını olumlu anlamda etkilediği pek çok çalışmada gösterilmiştir $(9,11,26-30)$.

\section{Bağlantı Dayanımının Değerlendirilmesi}

Ağız boşluğu dinamik bir ortamdır. Restorasyonlar ağız ortamında baskı, çekme ve sıkıştırmanın dahil olduğu oklüzal kuvvetlere maruz kalır. Farklı pH derecelerine sahip kimyasallar, sıcaklık değişimleri ve tükürük de ağız ortamında etkin olabilen diğer faktörlerdir. Bu durumlar restorasyonların, reçine siman ve diş arasındaki bağlantı dayanımını etkileyebilmektedir. Ağız ortamının koşullarını taklit edebilmek ve bağlantı dayanımını değerlendirmek amacıyla yapılan çeşitli laboratuvar testleri mevcuttur.

\section{1. Çekme ve makaslama testleri}

Seramik ve reçine siman arasındaki bağlanma dayanımını değerlendirmede sıklıkla kullanılan test yöntemleri çekme ve makaslama testleridir.

Çekme dayanım testleri diş veya reçine siman ile bağlantısı sağlanmış seramik yüzeylere dik olacak şekilde, yüzeyler birbirinden ayrılıncaya kadar kuvvet uygulanmasıyla gerçekleştirilir. Uygulanan maksimum kuvvetin örneklerin yüzey alanına bölünmesiyle hesaplanır. Makaslama testi, seramik yüzeyinin reçine ile bağlandığı ara yüze paralel kuvvet uygulanmasıyla gerçekleştirilir. İki yüzey birbirinden ayrilincaya kadar kuvvet uygulanır. Uygulanan maksimum kuvvetin ara yüz alanına bölünmesiyle hesaplanır (19).

Geleneksel çekme ve makaslama testlerinde meydana gelebilen eşit olmayan stres dağılımlarının önüne geçebilmek amacıyla mikro çekme ve mikro makaslama testleri geliştirilmiştir. Mikro düzeyde yapılan testlerde, örneklerden 1 mm2'lik kesitler alınır. Kesit alanının azaltılmasıyla; ara yüzde daha eşit stres dağılımı oluşur, materyalde koheziv ve simanda adeziv başarısızlık riski azalır. Bu durum Griffith kanunuyla açıklanabilmektedir. Seramik materyallerden elde edilen büyük kesitlerin yapıda büyük çatlaklar oluşturabileceği bu sebeple stres dağılımının eşit olmadığ düşünülmektedir $(15,18,19,26,27,31,32)$.

\section{Termal döngü testi}

Ağız ortamını taklit etmek amacıyla termal döngü ve mekanik döngü testleri yapılabilmektedir. $\mathrm{Bu}$ testler mekanik 
yaşlandırma etkisi yaratırlar. Termal döngü testlerinde örnekler sıcaklı̆̆ 5 ve $550 \mathrm{C}$ arasında değişen distile suda, 1000 veya 100,000 döngüye maruz birakilırlar. Materyallerin bağlantı ara yüzlerinde termal genleşme katsayılarındaki farklılıklar sebebiyle stres oluştururlar (33). Pek çok çalışmada termal döngü testinin seramik yüzeyi ve reçine siman arasındaki bağlantı dayanımını azalttığı gösterilmiştir $(18,27,32,34)$.

\section{Saklama koșulları}

Ağız ortamının nemli oluşu reçine siman ve seramik yüzeyi arasındaki bağlantı dayanımını olumsuz etkileyebilmektedir. Reçinenin nemli ortamda bekletilmesinin bağlantının hidrolitik olarak bozulmasına sebep olduğu gösterilmiştir (35). Kısa süreli saklama koşulu olarak $37^{\circ} \mathrm{C}$ distile suda 24 saatlik bekletme ISO/11405 standartlarında önerilmektedir. Pek çok çalışmada reçine siman ve seramiğin, 24 saatten 1 yıla kadar, distile suda bekletilmesinin bağlantı dayanımını olumsuz anlamda etkilediği gösterilmiştir $(11,16,17,26,27,33,35,36)$.

\section{Farklı Yüzey İşlemleri ve Bağlantı Dayanımına Etkilerinin Karşılaştırılması}

Monolitik seramik yüzeyine uygulanan farklı yüzey işlemleri ve bu işlemlerin bağlantı dayanımına etkisini karşılaştıran çalışmalar Tablo III' de gösterilmiştir. Türker ve ark. (36) yaptıkları bir çalışmada hibrit seramik ve reçine nano seramik blokların reçine siman ile bağlanma dayanımını makaslama testi ile değerlendirmişlerdir. Simantasyon öncesi yüzey işlemi olarak hidroflorik asit uygulama, tribokimyasal silika ile kaplama, kumlama, primer uygulama, lazer ile yüzey pürüzlendirme uygulanmıştır. Sonuçlara bakıldığında, yüzey işlemi uygulamalarının anlamlı olarak bağlanma dayanımını arttırdığı ve gruplar arasında en fazla bağlanma dayanımının hidroflorik asit ile yüzey pürüzlendirmenin ardından primer uygulanması sonucu elde edildiği görülmektedir. Lazer uygulama, tribokimyasal silika ile kaplama ve kumlamanın benzer sonuçlar verdiği görülmüsştür. Bu durum; seçilen seramik yüzeyler camsı faz içerdiği için hidroflorik asit ile pürüzlendirmenin etkili olup, kumlama ve tribokimyasal silika ile kaplama arasında anlamlı bir fark oluşmadığ 1 şeklinde açıklanabilir. Barutçigil ve ark. (37) tarafından yapılan farklı bir çalışmada hibrit seramiklere farklı yüzey işlemleri uygulanmıştır. Bu işlemler; asit ile pürüzlendirme, tribokimyasal silika ile kaplama, kumlama, MDP içerikli silan uygulama, Er,Cr:YSGG lazer ile pürüzlendirmedir. Makaslama testi sonuçlarına bakıldığında en yüksek bağlantı dayanımının silan uygulanmış grupta olduğu görülmektedir. Asit ile pürüzlendirme, tribokimyasal silika ile kaplama ve kumlama sırasıyla yüzey pürüzlendirme için önerilen işlemlerdir. Altan ve ark. (27) bir başka çalışmada ise iki farklı monolitik zirkonya, geleneksel zirkonya ve zirkonya ile güçlendirilmiş lityum disilikat bloklara farklı yüzey işlemleri uygulamıştır. Hidroflorik asit, kumlama, lazer uygulama, tribokimyasal silika ila kaplama ve kumlamayı takiben lazer uygulama işlemlerinin bağlantı dayanımına etkisi makaslama testiyle değerlendirmiştir. Kumlama ve tribokimyasal silika ile kaplamanın monolitik zirkonya bloklara bağlantı dayanımı açısından geleneksel zirkonya bloklara göre daha etkili olduğu görülmüștür.
Tablo III: Monolitik seramik yüzeylerine uygulanan yüzeyişlemleri ve bağlantı dayanımının değerlendirilmesine ait literatür çalışmaları.

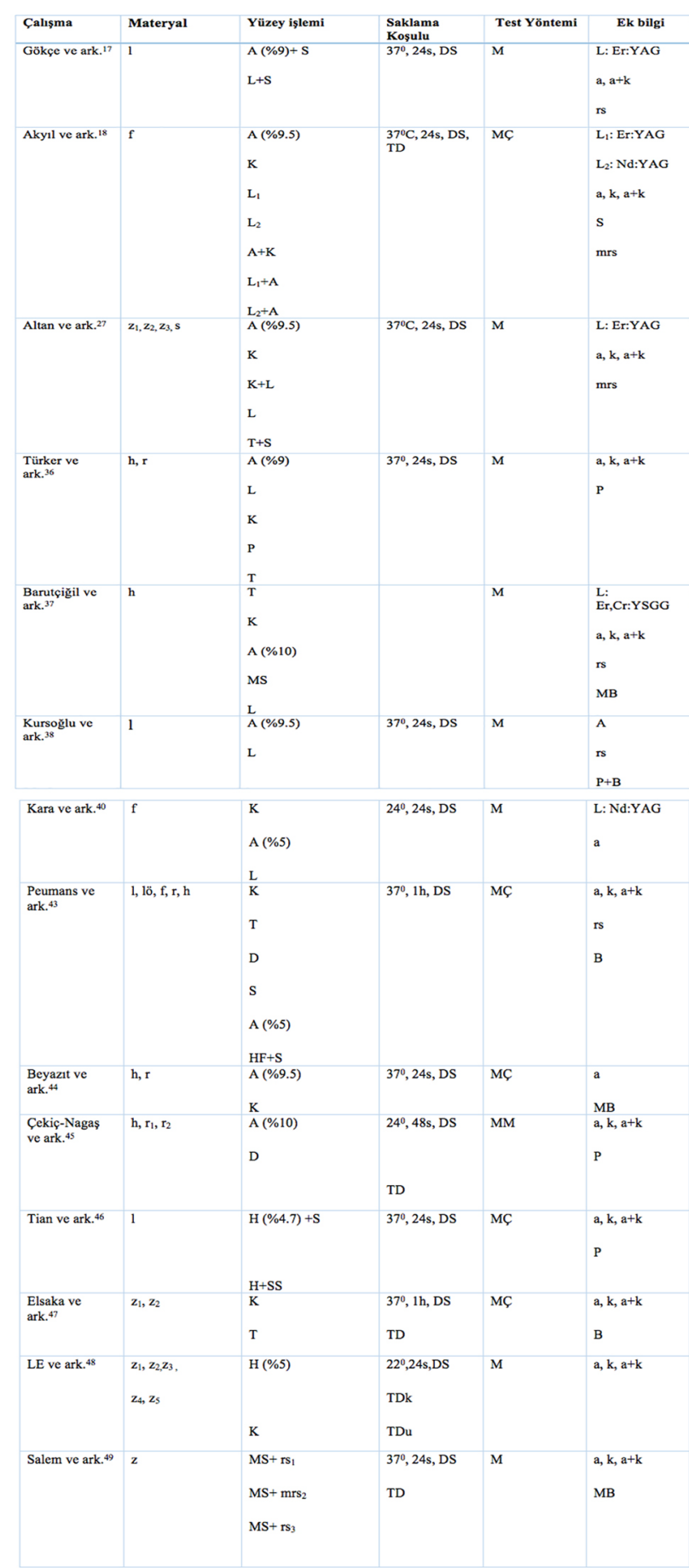

f;feldspatik seramik, lö;lösit ile güçlendirilmiş cam seramik, l; lityum disilikat ile güçlendirilmis cam seramik, h;hibrit seramik, r;reçine nano seramik, z;monolitik zirkonya, s;zirkonya ile güçlendirilmiş lityum disilikat A; hidroflorik asit, S; silan, MS;MDP içerikli silan, SS;sıcak hava basıncı ile silan uygulama, K;Al2O3 ile kumlama, L;lazer, T;tribokimyasal silika ile kaplama, D;döner alet ile pürüzlendirme, P;primer, B;bond, MB;MDP içerikli bond, TD;termal döngü, TDk;kısa süreli termal döndü, TDu;uzun süreli termal döngü, DS; distile su, Ç;çekme testi, M;makaslama testi, MÇ;mikroçekme testi, MM;mikro makaslama testi, a;adeziv başarısılık değerlendirme, k;koheziv başarısızlı değerlendirme, $a+k$;karma başarlsızlık değerlendirme, rs;reçine siman, mrs;MDP içerikli reçine siman 
Zirkonya ile güçlendirilmiş lityum disilikat bloklarda hidroflorik asit ile pürüzlendirmenin kumlama ve tribokimyasal silika ile kaplamaya göre daha etkili olduğu görülmüştür.

$\mathrm{Bu}$ durum materyalin camsı faz içeriğinden kaynaklı olup bir önceki çalışmayı destekler niteliktedir (36). Geleneksel zirkonyaya farklı lazer tipleri ve kumlama ile yüzey işlemi uygulanmış başka bir çalışmada ise (16) bağlantı dayanımı makaslama testi ile değerlendirilmiştir. Sonuçlara bakıldığında Er:YAG ve Nd:YAG lazerin kumlama ve CO2 lazere göre daha yüksek bağlanma dayanımı sağladığı görülmektedir. Kursoğlu ve ark. (38) lityum disilikat seramik yüzeyine farklı güçte lazer (Er,Cr:YSGG) ve asit uygulamış makaslama testi ile reçine simanın bağlantı dayanımını değerlendirmiştir.

Yüzey işlemi uygulanmış gruplarda, uygulanmamış olanlara göre anlamlı farklar oluşmuştur. Yüzey işlemi uygulanmış gruplara bakıldığında ise asitlenen seramik yüzeylerinin lazer uygulanmış olanlara göre çok daha yüksek bağlantı dayanımı sağladığı, lazer uygulanmış gruplar içinde ise, yüksek güçte lazer uygulanmış olanların daha yüksek dayanım verdiği görülmüştür. Akyıl ve ark. (18) tarafından yapılan bir başka çalışmada da cam seramik yüzeylerinde en etkili yüzey işleminin asitleme olduğu gösterilmiştir. Feldspatik seramikler, farklı yüzey işlemlerinin uygulandığ incelenmiştir. Bu işlemler; asit uygulama, kumlama, Er:YAG ve Nd:YAG lazer uygulama, asitleme ve kumlama, Er:YAG lazer uygulama ve asitleme, Nd:YAG lazer uygulama ve asitlemedir. Bağlantı dayanımını değerlendirmek amacıyla yapılan mikro çekme testi sonuçlarına bakıldığında, en yüksek bağlantı dayanımının sadece asitlenen daha sonra kumlama yapılan gruplarda olduğu görülmektedir. Lazer çeşitleri arasında anlamlı bir fark görülemezken, lazer uygulamasını takiben yüzeyi asitlemenin bağlantı dayanımını arttırdığı görülmüştür. Gökçe ve ark. (17) tarafindan yapılan bir çalışmada ise lityum disilikat içerikli tam seramik yüzeylerine farklı güçte Er:YAG lazer ve hidroflorik asit uygulanmıştır. Yapılan makaslama testi sonucunda yüksek güçte lazer uygulanmasının, hidroflorik aside benzer bağlantı dayanımı sağladığı ve bu durumun yüzey işlemi olarak kullanılabileceği gösterilmiş̧ir. Seramik yüzeylerine lazer uygulanmasının bağlantı dayanımına etkisini inceleyen bir meta analiz raporunda (39) yüzey işlemi uygulanmamış yüzeylere göre lazer uygulanmış olanların, bağlantı dayanımının daha yüksek olduğu belirtilmiştir. Lazer uygulama ile kumlama arasında anlamlı bir etki görülmemiştir. Seramik yüzeyine uygulanan lazer tipleri içerisinde $\mathrm{CO} 2$ lazerin daha etkili olduğu görülmektedir.

Cam seramik yüzeylerinin kumlama ile pürüzlendirilmesi, çok fazla aşınmaya sebep olabileceği ve çatlak oluşumunu arttırabileceği düşünceleriyle önerilen bir yüzey işlemi değildir (10). Kara ve ark. (40) feldspatik seramiklere kumlama, lazer ve asit ile pürüzlendirme işlemleri uygulamışlardır. Kumlama ile pürüzlendirilmiş yüzeylerin, asit ve lazer ile pürüzlendirilmiş olanlara göre daha pürüzlü yüzey sağladığ 1 ve bağlanma dayanımını arttırdığı görülmüştür. Lazer ve asit ile pürüzlendirme arasında anlamlı bir fark görülmemiștir. Ersu ve ark. (14) kumlamanın, asitleme ve lazere göre daha fazla yüzey pürüzlülüğü yarattığı fakat bu durumun bağlantı dayanımını etkilemediğini göstermiştir. $\mathrm{Bu}$ durumun, diğer çalışmalarda da belirtildiği gibi $(41,42)$, artan yüzey pürüzlülüğüne bağlı olarak mikro mekanik retansiyonun ve bağlantı dayanımının olumlu anlamda etkilenmesinden kaynaklandığı düşünülebilir.

Silika içerikli seramik yüzeylerine hidroflorik asit ile kimyasal yüzey işlemi uygulamanın bağlantı dayanımına en çok etki eden yöntem olduğu düşünülmektedir. Peumans ve ark. (43) yaptıkları bir çalışmada, altı farklı CAD/CAM destekli materyale mekanik ve kimyasal yüzey işlemleri uygulamışlardır. Feldspatik, lösit, lityum disilikat, hibrit seramik, reçine nano seramik ve zirkonya ile güçlendirilmiş lityum disilikattan oluşan gruplara mekanik ve kimyasal yüzey işlemleri uygulanmış olup iki farklı reçine siman ile seramik yüzeyler birbirine simante edilmiştir. Mikro çekme testi sonuçlarına bakıldığında, seramik çeşitlerinin her bir yüzey işleminden farklı anlamda etkilendiği görülmektedir. Cam seramiklere silan ve hidroflorik asit uygulanmasının bağlantı dayanımını anlamlı düzeyde etkilediği görülmektedir. Reçine infiltre seramiklere bakıldığında; reçine nano seramiklerde mekanik yüzey işlemlerinin daha fazla etkin olduğu, kimyasal yüzey işlemi olarak her iki grupta da silan ve asit uygulamanın etkili olduğu görülmüştür. Zirkonya infiltre lityum disilikat bloklarda ise asit uygulamanın etkili olduğu görülmüştür. Beyazıt ve ark. (44) hibrit seramik ve reçine nano seramik blokların hidroflorik asit ve kumlama sonucu iki farklı reçine siman ile bağlantı dayanımını incelemiş̧ir. Hibrit seramikler için kumlamanın, reçine nano seramikler için asitlemenin bağlantı dayanımı açısından daha uygun yüzey işlemleri olduğu sonucuna varılmıştır.

$\mathrm{Bu}$ sonuçlar bir önceki çalışmayla örtüşmektedir. Ancak Çekiç-Nagaş ve ark. (45) farklı reçine infiltre seramik bloklarda hidroflorik asit uygulamanın bağlantı dayanımına etkisinin olmadığını göstermiştir. Tian ve ark. (46) tarafından yapılan başka bir çalışmada da lityum disilikat yüzeyine hidroflorik asit ve silan uygulamasının seramik ve reçine siman arasındaki bağlantı dayanımını arttırdığı sonucuna varılmıştır. Fosfat monomeri içeren reçine simanların seramik ve reçine siman arasındaki bağlantı dayanımını arttırdığı literatürde gösterilmiştir. Elsaka (47) iki farklı monolitik zirkonya seramiğe kumlama ve tribokimyasal silika ile kaplama olmak üzere iki farklı yüzey işlemi uygulamıştır. Fosfat monomeri içeren ve içermeyen reçine simanlar ile bağlantı dayanımı değerlendirilmiştir. Tribokimyasal silika ile kaplamanın ve fosfat monomeri içeren simanların daha yüksek bağlantı dayanımı sağladığı görülmüștür. LE ve ark. (48) geleneksel zirkonya ve dört farklı monolitik zirkonyayı asitleme ve kumlama işlemlerine maruz bırakmıştır. Fosfat monomeri içeren reçine simanla simante edilen seramiklerin bağlantı dayanımına bakıldığında geleneksel ve monolitik zirkonya arasında anlamlı fark görülmemiştir. Kumlamanın ardından MDP içerikli reçine siman ile simante edilmesinin bağlantı dayanımını arttırdığı görülmüştür. Salem ve ark. (49) MDP içerikli reçine siman ve silanların monolitik zirkonya ile bağlantı dayanımına etkisini incele- 
miştir. En iyi bağlantı dayanımının hem silan hem de reçine simanda fosfat monomeri bulunan gruplarda oluştuğu gözlenmiştir. Farklı bir çalışmada, reçine infiltre seramik bloklara fosfat monomeri içeren silan uygulanmasının hidroflorik asitlemeye göre bağlantı dayanımını daha fazla arttırdığı görülmüştür (44). Türker ve ark. (36) fosfat monomeri içeren ve içermeyen iki farklı reçine simanı kıyaslamış ve sonuç olarak fosfat monomeri içerenlerde daha yüksek bağlantı dayanımı gözlemlemiştir. Satnish ve ark. (32) MDP içerikli siman ile simante edilen geleneksel zirkonya seramiklerin bağlantı dayanımının, MDP içermeyen siman ile simante edilenlere göre daha fazla olduğunu göstermiş̧tir. Geleneksel zirkonyanın bağlantı dayanımını değerlendiren bir literatür derlemesinde, tribokimyasal silika ile kaplamanın ardından fosfat monomeri içeren silan bağlayıcı ajan ve reçine siman kullanılmasının bağlantı dayanımını arttırdığı belirtilmiş̧ir (28). Zirkonyanın fosfat monomeri içeren adeziv ajanlar ile simantasyonunu gösteren bu çalışmalar birbiri ile örtüşmektedir. Peumans ve ark. (43) tarafından silika içerikli seramiklerle yapılan farklı bir çalışmada ise fosfat monomeri içermeyen siman gruplarında bağlantı dayanımının daha fazla olduğu görülmüştür. $\mathrm{Bu}$ durum, başka bir çalışmada da belirtildiği gibi, organik doldurucu oranı yüksek reçine simanların düşük olanlara göre daha yüksek bağlantı dayanımı sağlamasıyla açıklanabilir (45).

Çekme ve makaslama dayanım testleri; yöntemlerin sınırlamaları, testlerin doğruluğu ve klinik kullanıma aktarılmaları açısından çelişki yaratmaktadır (50). Sonlu elemanlar analizi çalışmalarıyla da gösterdiği üzere, (51-53) bağlantı ara yüzünde meydana gelen ve eşit olmayan stres dağllımına bağlı olarak kırılmaların başlaması sebebiyle doğru sonuçların elde edilememesi; bu çelişkinin başlıca sebebini oluşturmaktadır (54). Makro düzeyde yapılan bağlantı dayanım testleri tekrarlanabilir oluşları ve uygulama kolaylığı açısından avantaj sağlamaktadır. Bazı makaleler, makro ve mikro test yöntemleri arasında anlamlı fark olmadığını öne sürmektedir $(53,55,56)$. Ancak, Della Bona ve ark. (52) çekme bağlantı dayanım testinin ara yüzde makaslama testine göre daha eşit bir stres dağılımı sağladığını göstermiştir.

Bağlantı dayanımının değerlendirmesi amacıyla yapılan çalışmalarda, örnekler ağız ortamının değişken koşullarını taklit etme amaçlı distile suda bekletilip ve/veya termal döngüye maruz birakılırlar. Termal döngünün bağlantı dayanımını azalttığı pek çok çalışmada gösterilmiştir $(11,16,17,26,27,33-36,45-48)$. Ayrıca; termal döngünün distile suda bekletmeye göre, bağlantı dayanımını daha fazla düşürdüğü de görülmektedir $(45,47,48)$. Barbosa ve ark.(57) geleneksel zirkyonyanın bağlantı dayanımının, uzun süre suda bekletildiğinde kısa süreli bekletmeye göre daha fazla düşüş gösterdiğini belirtmiştir. Elsaka (47) tarafindan yapılan bir çalışmada ise uzun veya kısa süreli suda bekletme sonucunda zirkonyanın bağlantı dayanımı açısından bir fark görülmemiştir. Pereira ve ark. (58) uygulanan döngü sayısı az ve suda bekletme süresinin kisa olduğu zaman, termal döngünün bağlantı dayanımını arttırabildiğini göstermiştir.
Suda bekletilen örneklerde distile su kullanıldığı görülmektedir. Ağız ortamını taklit etme amacıyla, yapay tükürük kullanılması gerçeğe daha yakın sonuçlar elde etmek amacıyla tavsiye edilmektedir (19).

Bağlantı dayanımı, adeziv ve koheziv başarı veya başarısızlığa göre değerlendirilir. Adeziv başarısızlık reçine siman ve seramik yüzeyi arasında ayrılma, koheziv başarısızlık ise reçine simanın kendi içinde veya seramiğin kendi içinde ayrılması olarak tanımlanır. Karma başarısızlık ise hem materyallerin kendi içinde hem de bağlantı noktasındaki ayrılmadır (48). Adeziv başarısızlık genellikle düşük bağlantı dayanımı sonucu görülür. Bu sebeple koheziv veya karma başarısızlıklar klinik anlamda daha tercih edilebilir durumlardir (47). Mevcut makalede; adeziv, koheziv ve karma başarısızlıkları içeren literatür çalışmalarına yer verilmiştir (17,18,27,36-38,40,43-49). Mikro çekme testlerinde görülen koheziv başarısızlıkların, örneklerin hazırlanması sırasında uzun eksen boyunca kesilmesi veya var olan çatlakların ilerlemesi sebebiyle oluşabileceği düşünülmektedir. Mikro çekme test yöntemi ile bağlantı dayanımını değerlendiren çalışmalarda görülen koheziv başarısızlıklar mevcuttur $(18,43,46,47)$. Bu örneklerin çalışma sonuçlarına dahil edilmemesi önerilmektedir (59-63).

\section{SONUÇ}

$\mathrm{Bu}$ literatür derlemesinden elde edilen sonuçlara göre:

1. Seramik yüzeyine uygulanan kimyasal ve mekanik işlemler bağlantı dayanımını arttırmaktadır.

2. Uygulanacak yüzey işlemi materyalin türüne göre seçilmelidir.

3. Silika içerikli seramiklerde ve zirkonya yüzeyinde uygula nacak mekanik yüzey işlemleri içerisinde kumlamanın en etkin sonuç verdiği görülmektedir. Döner alet ile pürüzlendirme işlemi klinik kullanım kolaylı̆̆ sağlasa da çatlak oluşumu ve ilerlemesine sebep olabileceği için önerilmemektedir. Lazer ile pürüzlendirme tek başına yeterli bağlantı dayanımı sağlamadığı için sonrasında seramik yüzeyine adeziv ajanların uygulanması önerilmek tedir.

4. Silika içerikli seramiklere uygulanan kimyasal yüzey işlemlerine bakıldığında cam seramiklere hidroflorik asit uygulanmasının ardından MDP içerikli silan kullanıl masının bağlantı dayanımını arttırdığı görülmüştür. Reçine infiltre seramiklerde; hibrit seramiklerde en etkin yüzey işleminin MDP içerikli silan uygulanmasının ardın dan MDP içerikli reçine siman ile simantasyon olduğu görülmüştür. Reçine nano seramiklerde silan uygulanması ve yüzeyin hidroflorik ile asitlenmesinin bağlantı dayanımını arttırdığı görülmüştür. Zirkonyum silikat ile güçlendirilmiş lityum disilikat için en etkin yüzey işlemi nin hidroflorik asit uygulama daha sonra tribokimyasal silika ile kaplama olduğu görülmektedir. Zirkonyanın adeziv simantasyon öncesi mutlaka tribokimyasal silika ile kaplanması gerekmektedir. Ardından MDP içerikli silan uygulanıp, reçine siman ile simantasyonu önerilmek tedir. 
Monolitik CAD/CAM Bloklara Uygulanan Farklı Yüzey Uygulamaları ve Simanlarla Bağlantı Kuvvetine Güncel Bakış

5. Adeziv simantasyon için organik doldurucu oranı yüksek ve MDP içerikli reçine siman kullanılmasının daha yüksek bağlantı dayanımı sağladığı belirtilmiştir.

6. Bağlantı dayanımını değerlendirmede kullanılan test yöntemleri arasında anlamlı bir fark görülmezken, mikro test yöntemlerinin gerçeğe daha yakın sonuçlar verdiği düşünülmektedir.
7. Ağız ortamını taklit etme amaçlı uygulanan yapay yaşlandırma yöntemleri içinde termal döngünün bağlantı dayanımını daha fazla etkilediği görülmüştür. 


\section{KAYNAKLAR}

1. Albashaireh ZS, Ghazal M, Kern M. Two-body wear of different ceramic materials opposed to zirconia ceramic. J Prosthet Dent 2010; 104:105-113.

2. Preis V, Behr M, Kolbeck C, Hahnel S, Handel G, Rosentritt M. Wear performance of substructure ceramics and veneering porcelains. Dent Mater 2011; 27:796-804.

3. Rosentritt M, Preis V, Behr M, Hahnel S, Handel G, Kolbeck C. Two-body wear of dental porcelain and substructure oxide ceramics. Clin Oral Investig 2012; 16:935-943.

4. Jung YS, Lee JW, Choi YJ, Ahn JS, Shin SW, Huh JB. A study on the in-vitro wear of the natural tooth structure by opposing zirconia or dental porcelain. J Adv Prosthodont 2010; 2:111-115.

5. Stawarczyk B, Ozcan M, Schmutz F, Trottmann A, Roos M, Hämmerle CHF. Two-body wear of mono- lithic, veneered and glazed zirconia and their corre- sponding enamel antagonists. Acta Odontol Scand 2013; 71:102-112.

6. Fahl N Jr, McLaren EA, Margeas RC. Monolithic vs. layered restorations: considerations for achieving the optimum result. Compend Contin Educ Dent 2014; 35:78-9.

7. Gracis S, Thompson VP, Ferencz JL, Silva NR, Bonfante EA. A new classification system for all-ceramic and ceramic-like restorative materials. Int $\mathrm{J}$ Prosthodont 2015; 28: 227-235.

8. Conrad HJ, Seong WJ, Pesun IJ. Current ceramic materials and systems

with clinical recommendations: a systematic review. J Prosthet Dent 2007;98: 389-404.

9. Yoshida K, Tsuo Y, Atsuta M. Bonding of dual-cured resin cement to zirconia ceramic using phosphate acid ester monomer and zirconate coupler. J Biomed Mater Res B Appl Biomater 2006; 77:28-33.

10. Thompson J, Stoner B, Piascik J, Smith R. Adhesion/cementation to zirconia and other non-silicate ceramics: Where are we now Dent Mater 2011;27: 71-82.

11. Miyahara H, Ikeda H, Fujio Y, Yoshii S, Nagamatsu Y, Chiaki K, Shimizu H. Chemical alteration of Ag-Pd-Cu-Au alloy surface by alumina air-abrasion and its effect on bonding to resin cement. Dental Materials Journal 2019;38: 630-637.
12. Valandro LF, Ozcan M, Bottino MC, Bottino MA, Scotti $\mathrm{R}$, Bona $\mathrm{AD}$. Bond strength of a resin cement to high-alumina and zirconia-reinforced ceramics: the effect of surface conditioning. J Adhes Dent 2006;8: 175-181.

13. Moretto SG, de Freitas PM, Inca HEC, Cesar PF, Bello-Silva MS, de Paula Eduardo C. Influence of Er:YAG laser surface treatment on flexural and bond strengths to glass-infiltrated zirconia-reinforced ceramic. Lasers Med Sci. 2020. doi; 10.1007/s10103-020-03205-w

14. Ersu B, Yuzugullu B, Ruya Yazici A, Canay S. Surface roughness and bond strengths of glass-infiltrated alumina-ceramics prepared using various surface treatments. J Dent 2009;37:848-56.

15. de Paula Eduardo C, Bello-Silva MS, Moretto SG, Cesar PF, de Freitas PM Microtensile bond strength of composite resin to glass-infiltrated alumina composite conditioned with Er,Cr:YSGG laser. Lasers Med Sci 2012; 27:7-14.

16. Akin H, Ozkurt Z, Kirmali O, Kazazoglu E, Ozdemir A. Shear bond strength of resin cement to zirconia ceramic after aluminum oxide sandblasting and various laser treatments. Photomed Laser Surg 2011; 29:797-802.

17. Gokce B, Ozpinar B, Dundar M, Comlekoglu E, Sen BH, Gungor MA. Bond strengths of all-ceramics: acid vs laser etching. Oper Dent 2007; 32:173-8.

18. Akyil MS, Yilmaz A, Bayindir F, Duymus ZY. Microtensile bond strength of resin cement to a feldspathic ceramic. Photomed Laser Surg 2011; 29:197-203.

19. Tian T, Tsoi JK, Matinlinna JP, Burrow MF. Aspects of bonding between resin luting cements and glass ceramic materials. Dent Mater 2014;30: e147-62.

20. Yu H, Du C, Cao Y. Shear bond test of hf acid etching machinable porcelain bonded to enamel with different concentration and disposing time. Hua Xi Kou Qiang Yi Xue Za Zhi 1998; 16:169-71.

21. Pattanaik S, Wadkar AP. Effect of etchant variability on shear bond strength of all ceramic restorations - an in vitro study. J Indian Prosthodont Soc 2011; 11:55-62.

22. Barghi N, Fischer DE, Vatani L. Effects of porcelain leucite content, types of etchants, and etching time on porcelain-composite bond. J Esthet Restor Dent 2006; 18:47-52.

23. Shimada Y, Yamaguchi S, Tagami J. Micro-shear bond strength of dual-cured resin cement to glass ceramics. Dent Mater 2002; 18:380-8. 
24. Ozcan M. The use of chairside silica coating for different dental applications: a clinical report. J Prosthet Dent 2002; 87:469-72.

25. Xible AA, de Jesus Tavarez RR, de Araujo CRP, Bonachela WC. Effect of silica coating and silanization on flexural and composite-resin bond strengths of zirconia posts: An in vitro study. J Prosthet Dent 2006;95: 224-229.

26. Bielen V, Inokoshi M, Munck JD, Zhang F, Vanmeensel K, Minakuchi S, Vleugels J, Naert I, Van Meerbeek B. Bonding Effectiveness to Differently Sandblasted Dental Zirconia. J Adhes Dent 2015; 17:235-42.

27. Altan B, Cinar S, Tuncelli B. Evaluation of shear bond strength of zirconia-based monolithic CAD-CAM materials to resin cement after different surface treatments. Niger J Clin Pract 2019; 22:1475-1482.

28. Bona AD, Pecho OE, Alessandretti R. Zirconia as a Dental Biomaterial. Materials (Basel) 2015; 4;8:4978-4991.

29. Tanaka R, Fujishima A, Shibata Y, Manabe A, Miyazaki T. Cooperation of phosphate monomer and silica modification on zirconia. J Dent Res 2008; 87:666-670.

30. Senyilmaz DP, Palin WM, Shortall ACC, Burke FJT. The effect of surface preparation and luting agent on bond strength to a zirconium-based ceramic. Oper Dent 2007; $32: 623-630$.

31. Pisani-Proenca J, Erhardt MC, Valandro LF, Gutierrez-Aceves G, Bolanos-Carmona MV, Del Castillo-Salmeron R, Bottino MA. Influence of ceramic surface conditioning and resin cements on microtensile bond strength to a glass ceramic. J Prosthet Dent 2006; 96:412-7.

32. Sathish S, Lakshmi S, Patel P, Annapoorni H. Effect of thermocycling on the micro-tensile bond strength between self-adhesive resin cement and nonphosphate monomer cements on zirconium-oxide ceramics. Indian J Dent Res 2019; 30:73-79.

33. Crim GA, Swartz ML, Phillips RW. Comparison of four thermocycling techniques. J Prosthet Dent 1985; 53:50-3.

34. Kansal R, Rani S, Kumar M, Kumar S, Issar G. Comparative evaluation of shear bond strength of newer resin cement (RelyX ultimate and RelyX U200) to lithium disilicate and zirconia ceramics as influenced by thermocycling. Contemp Clin Dent 2018; 9:601-6.

Loher H, Behr M, Hintereder U, Rosentritt M, Handel G. ygulamaları ve Simanlarla Bağlantı Kuvvetine Güncel Bakış

35. The impact of cement mixing and storage errors on the risk of failure of glass-ceramic crowns. Clin Oral Investig 2009; 13:217-22.

36. Turker N, Buyukkaplan UŞ, Başar EK, Özarslan MM. The effects of different surface treatments on the shear bond strengths of two dual-cure resin cements to $\mathrm{CAD} /$ CAM restorative materials. J Adv Prosthodont 2020; 12:189-96

37. Barutcigil K, Barutcigil Ç, Kul E, Özarslan MM, Buyukkaplan US. Effect of Different Surface Treatments on Bond Strength of Resin Cement to a CAD/CAM Restorative Material. J Prosthodont 2019; 28:71-78.

38. Kursoğlu P, Motro PF, Yurdaguven H. Shear bond strength of resin cement to an acid etched and a laser irradiated ce- ramic surface. J Adv Prosthodont 2013; 5:98-103.

39. García-Sanz V, Paredes-Gallardo V, Mendoza-Yero O, Carbonell-Leal M, Albaladejo A, Montiel-Company JM, Bellot-Arcís C. The effects of lasers on bond strength to ceramic materials: A systematic review and meta-analysis. PLoS One 2018 ;2;13: e0190736.

40. Kara HB, Ozturk AN, Aykent F, Koc O, Ozturk B. The effect of different surface treatments on roughness and bond strength in low fusing ceramics. Lasers Med Sci $2011 ; 26: 599-604$.

41. Hummel M, Kern M. Durability of the resin bond strength to the alumina ceramic Procera. Dent Mater 2004; 20:498-508

42. Won-suck O, Shen C. Effect of surface topography on the bond strength of a composite to three different types of ceramic. J Prosthet Dent 2003; 90:241-246

43. Peumans M, Valjakova EB, De Munck J, Mishevska CB, Van Meerbeek B. Bonding Effectiveness of Luting Composites to Different CAD/CAM Materials. J Adhes Dent 2016; 18(4):289-302.

44. Bayazıt EÖ. Microtensile Bond Strength of Self-Adhesive Resin Cements to CAD/CAM Resin-Matrix Ceramics Prepared with Different Surface Treatments. Int J Prosthodont 2019; 32:433-438.

45. Cekic-Nagas I, Ergun G, Egilmez F, Vallittu PK, Lassila LV. Micro-shear bond strength of different resin cements to ceramic/glass-polymer CAD-CAM block materials. J Prosthodont Res 2016; 60:265-273. 
Uğuz Ş.D. ve Turp V.

46. Tian T, Tsoi JKH, Matinlinna JP, Burrow MF. Evaluation of microtensile bond strength on ceramic-resin adhesion using two specimen testing substrates Int J Adhes 2014; 54:165-71.

47. Elsaka SE. Influence of surface treatments on the bond strength of resin cements to monolithic zirconia. J Adhes Dent 2016; 18:387-395.

48. LE M, Larsson C, Papia E. Bond strength between MDP-based cement and translucent zirconia. Dent Mater J 2019; 38:480-489.

49. Salem RST, Ozkurt-Kayahan Z, Kazazoglu E. In Vitro Evaluation of Shear Bond Strength of Three Primer/Resin Cement Systems to Monolithic Zirconia. Int J Prosthodont 2019; 32:519-525.

50. Liu Q, Meng XF, Ding H, Luo XP. The comparative research on resin bond strength and durability of two machinable glass ceramic. Hua Xi Kou Qiang Yi Xue Za Zhi 2011; 29. p. 129-131.

51. Dehoff PH, Anusavice KJ, Wang ZX. 3-Dimensional finite-element analysis of the shear bond test. Dent Mater 1995 ; $11: 126-31$.

52. Della Bona A, van Noort R. Shear vs. tensile bond strength of resin composite bonded to ceramic. J Dent Res 1995; 74:1591-6.

53. Jin XZ, Homaei E, Matinlinna JP, Tsoi JKH. A new concept and finite-element study on dental bond strength tests. Dent Mater 2016; 32: e238-e250.

54. Moharamzadeh K, Hooshmand T, Keshvad A, Van Noort R. Fracture toughness of a ceramic-resin interface. Dent Mater 2008; 24:172-7.

55. Braga RR, Meira JB, Boaro LC, Xavier TA. Adhesion to tooth structure: a critical review of "macro" test methods. Dent Mater 2010; 26: e38-49.

56. Valandro LF, Ozcan M, Amaral R, Vanderlei A, Bottino MA. Effect of testing methods on the bond strength of resin to zirconia-alumina ceramic: microtensile versus shear test. Dent Mater J 2008; 27:849-55.

57. de Sá Barbosa WF, Aguiar TR, Francescantonio MD, Cavalcanti AN, de Oliveira MT, Giannini M. Effect of water storage on bond strength of self-adhesive resin cements to zirconium oxide ceramic. J Adhes Dent 2013; 15:145-50.
58. Pereira PC, Castilho AA, Souza RO, Passos SP, Takahashi FE, Bottino MA. A comparison of the film thickness of two adhesive luting agents and the effect of thermocycling on their microTBs to feldspathic ceramic. Acta Odontol Latinoam 2009; 22:191-200.

59. Scherrer SS, Cesar PF, Swain MV. Direct comparison of the bond strength results of the different test methods: a critical literature review. Dent Mater 2010;26: e78-93.

60. Sirisha K, Rambabu T, Ravishankar Y, Ravikumar P. Validity of bond strength tests: A critical review-Part II. J Conserv Dent 2014; 17:420-6.

61. Cho BH, Dickens SH. Effects of the acetone content of single solution dentin bonding agents on the adhesive layer thickness and the microtensile bond strength. Dent Mater 2004; 20:107-15.

62. Sadek FT, Cury AH, Monticelli F, Ferrari M, Cardoso PE. The influence of the cutting speed on bond strength and integrity of microtensile specimens. Dent Mater 2005; 21:1144-9.

63. Sadek FT, Monticelli F, Muench A, Ferrari M, Cardoso PE. A novel method to obtain microtensile specimens minimizing cut flaws. J Biomed Mater Res B Appl Biomater 2006; 78:7-14. 